\title{
HISTÓRIAS DESMEDIDAS: REFLEXÕES SOBRE EXPERIÊNCIAS DE EXTENSÃO COM JOVENS (IN)VISIBILIZADOS
}

GOMES, C.J. de A. ${ }^{1}$, BARROS, J.P.P. ${ }^{2}$, CAVALCANTE, C.O.B. ${ }^{3}$, NUNES, L.F. ${ }^{4}{ }^{2}$ ALENCAR, F.A.B. ${ }^{5}$

${ }^{1}$ Graduanda em Psicologia pela Universidade Federal do Ceará (UFC). Bolsista de Iniciação Científica. Integrante do VIESES. E-mail: carlajessicagomes@alu.ufc.br; ${ }^{2}$ Professor do Departamento de Psicologia e do Programa de Pós-Graduação em Psicologia da Universidade Federal do Ceará (UFC). Coordenador do VIESES: Grupo de Pesquisas e Intervenções sobre Violência, Exclusão Social e Subjetivação. Email: joaopaulobarros07@gmail.com; ${ }^{3}$ Mestre em Psicologia pela Universidade Federal do Ceará (UFC). E-mail:

clara.oliveira0305@gmail.com; ${ }^{4}$ Doutoranda em Psicologia pela Universidade Federal do Ceará (UFC). Integrante do VIESES. E-mail: larissafnpsico@gmail.com; ${ }^{5}$ Mestre em Psicologia pela Universidade Federal do Ceará (UFC).E-mail:alencar.filipe@gmail.com.

Artigo submetido em janeiro de 2019 - DOI 10.32356/exta.v19.n1.40240

\section{RESUMO}

Este artigo objetiva relatar experiências do projeto de extensão Histórias Desmedidas de 2016 a 2018, junto a jovens, de 15 a 29 anos, em cumprimento de medida socioeducativa na cidade de Fortaleza e em situação de encarceramento. O projeto ampara-se teórico-metodologicamente no campo da Psicologia Social, em seus diálogos com estudos pós estruturalistas, da criminologia crítica e críticos à colonialidade, bem como com produções de áreas afins que tematizam criticamente juventudes, violências e políticas públicas. $\mathrm{O}$ projeto se operacionalizou, nestes anos, em duas frentes de ação: a primeira consistiu na realização de atividades com adolescentes e jovens em cumprimento de medida socioeducativa de meio aberto, mediante a metodologia de oficinas, enquanto a segunda se voltou à incidência técnicopolítica nos sistemas socioeducativo e prisional a partir da participação em comissões e comitês ligados aos monitoramentos realizados por organizações da sociedade civil atuantes da defesa de direitos humanos. As ações do projeto foram registradas a partir de diários de campo ao longo do processo e de relatórios, ao final de cada ano. Nos resultados, apresentamos a participação da equipe de extensão na facilitação de 32 oficinas com adolescentes e jovens em cumprimento de medida de liberdade assistida e prestação de serviço à comunidade, no $4^{\circ}$ monitoramento do sistema socioeducativo realizado pelo Fórum-DCA e no Comitê Estadual de Monitoramento da Política Nacional para Mulheres Privadas de Liberdade e Egressas do Sistema Prisional. Concluímos este artigo reiterando a importância de tais experiências extensionistas para a formação em psicologia a partir de um paradigma ético-estético-político.

PALAVRAS-CHAVE: Juventudes. Direitos Humanos. Socioeducação. Violências. Psicologia Social.

\section{HISTÓRIAS DESMEDIDAS: REFLECTIONS ON EXTENSION EXPERIENCES WITH YOUNG PEOPLE (IN)VISIBILIZED}

\begin{abstract}
This article aims to report experiences of the extension project Histórias Desmedidas from 2016 to 2018, with young people from 15 to 29 years old, in accordance with a socio-educational measure in the city of Fortaleza and in a situation of incarceration. The project is supported theoretically and methodologically in the field of social psychology, in its dialogues with post-structuralist studies, critical criminology and coloniality, as well as with productions from related areas that critically address youth, violence and public policies. In these years, the project was operationalized on two fronts of action: the first consisted of activities with adolescents and young people in accordance with an open socio-educational measure, through the methodology of workshops, while the second turned to technical-impact political in the socio-educational and penitentiary systems,
\end{abstract}

based on participation in commissions and committees linked to the monitoring carried out by civil society organizations working in the defense of human rights. The project's actions were recorded in field diaries throughout the process and reports, at the end of each year. In the results, we present the participation of the extension team in facilitating 32 workshops with adolescents and young people, in accordance with the measure of assisted freedom and provision of services to the community, in the 4th monitoring of the socioeducational system carried out by the Forum-DCA and by the State Committee Monitoring of the National Policy for Women Deprived of Liberty and Prisoners. We conclude this article by reiterating the importance of these extension experiences for training in psychology from an ethical-aesthetic-political paradigm.

KEYWORDS: Youth. Human rights. Socioeducation. Violence. Social Psychology. 


\section{INTRODUÇÃO}

O presente artigo tem por intuito apresentar ações de 2016 a 2018 do projeto de extensão "Histórias Desmedidas", ligado ao VIESES: Grupo de Pesquisas e Intervenções sobre Violências, Exclusão Social e Subjetivação, do Departamento de Psicologia da Universidade Federal do Ceará (UFC). Criado em 2016, os objetivos do Projeto, até o ano de 2019, foram construir espaços de problematização com jovens em cumprimento de medida socioeducativa e jovens em situação de encarceramento acerca de suas trajetórias e perspectivas de vida, bem como fortalecer a incidência técnica da Psicologia em processos de monitoramento dos sistemas socioeducativo e prisional locais.

A proposta da ação de extensão se justifica pela conexão de quatro problemáticas identificadas no Brasil e acentuadas na realidade do Ceará: 1) a gravidade da questão da violência urbana e de seus impactos em termos de criminalização e extermínio de juventudes negras, empobrecidas e periferizadas; 2) condições aviltantes dos sistema prisional e socioeducativo em termos da garantia de direitos humanos e responsabilização na atualidade, no âmbito das medidas de privação de liberdade e em meio aberto; 3) o desafio de problematizar o imaginário social que associa juventude, pobreza, raça, risco, periculosidade e violência (HILLESHEIM; CRUZ, 2008; BARROS, 2019; BARROS et al., 2019a; BARROS et al., 2019b; BARROS et al., 2019c; BARROS et al., 2019d), a partir da coletivização de exercícios analíticos acerca das relações entre juventude e violência, em contraposição à lógicas de patologização, sujeição criminal e desumanização de certas juventudes; 4) a necessidade de exercitar a (re)invenção de práticas psicossociais junto a adolescentes "em conflito com a lei" e jovens encarcerados/as, em contraponto a perspectivas que, a partir da institucionalização da figura do "sujeito infrator", atualizam lógicas coloniais, a partir de um motor racializante e punitivista que estigmatiza e segrega esses sujeitos.

Denunciando e enfrentando tais problemáticas, o projeto busca a desnaturalização de processos de violação de direitos e assujeitamentos juvenis, e, ainda, o compartilhamento e a ressignificação de histórias por vezes invisíveis e inaudíveis socialmente, com vistas à experimentação da produção de novos territórios existenciais juvenis. 


\section{CONTEXTUALIZAÇÃO E ASPECTOS TEÓRICOS}

Situada no campo da Psicologia Social e Psicologia Jurídica, a proposta de extensão estabelece conexões com estudos pós-estruturalistas, da criminologia crítica (BATISTA, 2003; WACQUANT, 2012) e de estudos críticos à colonialidade (MBEMBE, 2014; 2017), bem como produções de áreas afins sobre violência, juventudes e políticas públicas. Tal composição plural mostra-se potente à análise e criação de agenciamentos coletivos produtores de modos heterogêneos de existencialização juvenis na contemporaneidade.

No que se refere à capital cearense, em 2012, Fortaleza apresentou o maior IHA entre as capitais do Brasil (MELO; CANO, 2014). Apesar dos dados demonstrarem que a população infantojuvenil é o principal alvo de violências letais, estes são frequentemente vistos como principais algozes do problema da violência urbana, sobretudo pela exploração de episódios de violência urbana praticados por esses segmentos sob a ótica de um populismo penal e de um sensacionalismo midiático, ensejando persistentes apelos pela ampliação de dispositivos punitivos a segmentos específicos da população, notadamente negros e pobres, como forma de gestão da insegurança social (CERQUEIRA et al., 2018).

O Ceará vem ganhando destaque nacional e internacional devido ao agravamento da segurança pública e do sistema prisional locais, bem como pela precária condução das medidas socioeducativas nas unidades de privação de liberdade. A situação de superlotação vivida no contexto cearense é fruto de anos de desmantelamento do sistema socioeducativo em âmbito local, mas também de um processo internacional e nacional. Frente à gravidade da situação cearense, a Corte Interamericana de Direitos Humanos notificou o Estado brasileiro após denúncia da situação do sistema socioeducativo no Ceará (CEDECA, 2014).

O cenário de colapso dos contextos das medidas socioeducativas também se materializa nas medidas em meio aberto (prestação de serviços à comunidade (PSC) e liberdade assistida (LA)), especialmente pela falta de investimentos por parte das prefeituras municipais.

\section{DELINEAMENTO METODOLÓGICO DO PROJETO}

O projeto se operacionalizou a partir de duas frentes de ação. A primeira voltou-se à construção de dispositivos grupais (BARROS, 1997; BARROS; SILVA; GOMES, 2020), a partir da metodologia de oficinas, com adolescentes que cumpriam medida socioeducativa em meio aberto e egressos do sistema socioeducativo sobre temáticas escolhidas pelos próprios 
participantes e que permitissem diálogos sobre condições juvenis na atualidade, suas trajetórias e perspectivas de vida, bem como sobre temáticas ligadas à cidadania e responsabilização juvenil, com vistas a potencializar a produção micropolítica de processos de singularização (GUATTARI; ROLNIK, 2005) entre os participantes. Ao todo, ao longo desses três anos, foram realizadas 32 oficinas. Já a segunda frente se desenvolveu a partir da participação em comitês e comissões concernentes aos processos de monitoramento dos sistemas socioeducativo e prisional, mediante a articulação de entidades da sociedade civil atuantes na defesa de direitos humanos em Fortaleza. Assim, participamos da comissão de monitoramento do sistema socioeducativo do Fórum Permanente de ONGs de Defesa dos Direitos de Crianças e Adolescentes do Ceará (Fórum DCA) e do Comitê de Monitoramento da Política Nacional para Mulheres Privadas de Liberdade e Egressas do Ceará.

Considerando essas frentes de ação, este artigo organiza seu relato a partir dos registros de diário de campo das experiências extensionistas do Histórias Desmedidas nos anos 2016, 2017 e 2018, junto a dois públicos principais: adolescentes e jovens em cumprimento de medida socioeducativa e, especificamente em 2018, também mulheres encarceradas no estado. O material de análise deste relato é oriundo da articulação dos registros de campo com reflexões teóricas produzidas ao longo das supervisões do projeto, a partir de autoras/es que permitiram pensar sobre relações entre juventudes, violências, modos de subjetivação, processos de criminalização e punição no Brasil (MISSE, 2014; BATISTA, 2003; DIÓGENES, 2009; SALES, 2007; WACQUANT, 2012; BORGES, 2018), bem como suas heranças coloniais (MBEMBE, 2014; 2017) e suas relações com processos de subjetivação capitalistas (GUATTARI; ROLNIK, 2005; ROLNIK, 2018).

Assim, as reflexões que constarão a seguir estão organizados a partir de analisadores que mais se sobressaíram nas narrativas dos/as participantes sobre seus cotidianos e nas práticas institucionais focalizadas pelos objetivos do projeto acima expostos. Nossa aposta é de que as ferramentas metodológicas inter(in)ventivas do projeto possuem potencial de reinvenção

permanente da psicologia à luz de paradigma ético-estético-político, anticolonial, antirracista e abolicionista penal (BARROS et al, 2017). 


\section{RESULTADOS E DISCUSSÕES}

\subsection{Oficinas temáticas com adolescentes em cumprimento de medidas socioeducativas de meio aberto.}

No tocante à sua primeira frente, o projeto realizou oficinas temáticas com adolescentes em cumprimento de medidas de LA e PSC em equipamentos da Rede Cuca (de 2016 a 2018) e em um dos Centro de Referência Especializado de Assistência Social (CREAS) de Fortaleza (2018). No CUCA Barra, foram realizadas 7 oficinas em 2016 e 8 oficinas em 2017, cujas temáticas foram escolhidas pelos próprios participantes, tais como: juventudes, direitos humanos, desigualdades sociais, profissionalização, violências, responsabilização juvenil e projetos de futuro. Em 2017, além da discussão de temas, ao final de cada oficina, os participantes eram mobilizados a produzir alguma materialidade informativa sobre a temática discutida, a ser compartilhada com outros jovens frequentadores do CUCA, tais como cartazes sobre o Estatuto da Criança e do Adolescentes (ECA) e um vídeo apresentando o CUCA sob o olhar de quem o frequenta. Além disso, em 2017 e 2018, houve o acompanhamento do Plano Individual de Atendimento (PIA) de adolescentes em cumprimento de PSC no CUCA Mondubim e a produção de oficinas e 16 spots sobre o tema da redução da maioridade penal, em parceria com a Rádio Cuca.

No primeiro semestre de 2018, a equipe de extensionistas se inseriu no CREAS da Secretaria Executiva Regional V (SER V), que atende pessoas do Grande Bom Jardim e Mondubim, através do acompanhamento de 5 encontros de um grupo de aproximadamente 15 jovens que cumpriam medida socioeducativa de LA. As discussões foram conduzidas por educadores sociais vinculados ao Programa Ceará Pacífico e ao Centro Cultural do Bom Jardim, contratados pelo Governo do Estado do Ceará, e exploraram temáticas relacionadas ao racismo, à cultura hip hop, à cultura negra e à capoeira como expressão cultural. Após o término do grupo, a inserção dos extensionistas continuou por meio do acompanhamento de três acolhidas, momentos em que a equipe do equipamento recepcionava e expunha aos novos adolescentes e jovens responsabilizados com medida socioeducativa de PSC ou de LA e ao responsável que os acompanham como funciona o cumprimento da medida.

No segundo semestre de 2018, as ações continuaram sendo realizadas no CREAS SER $\mathrm{V}$, com um total de 12 oficinas, sendo destas 6 temáticas, as quais abordaram os seguintes 
temas: juventude e cidadania; direitos humanos e instituições; violência institucional e formas de enfrentamento; discriminação e resistências populares; responsabilização juvenil e projetos futuros; e educação, liberdade e convivialidade, e as 6 oficinas restantes se dividindo em 3 de vídeo e 3 de graffiti. As 12 oficinas ocorreram com frequência semanal, com a participação de 16 jovens no total, incluindo socioeducandos em cumprimento de LA, familiares e egressos do sistema socioeducativo do estado do Ceará. Essas atividades foram realizadas em parceria com o projeto de extensão "Traficando Saberes", do Laboratório de Estudos da Violência (LEV), vinculado ao Departamento de Ciências Sociais da UFC, que construiu as oficinas junto aos extensionistas do "Histórias Desmedidas", e com a ONG Visão Mundial e o CEDECA-CE, através do apoio logístico.

Nas oficinas realizadas em 2016, 2017 e 2018, os adolescentes e jovens, em sua maioria do sexo masculino, relataram vivências relacionadas aos seus cotidianos e às suas trajetórias socioinstitucionais. Sobressaíram-se relatos atravessados pela criminalização e sujeição criminal dessas juventudes, envolvendo racismo e experiências de violências institucionais (DIÓGENES, 2009; MBEMBE, 2014; WACQUANT, 2012; BARROS, 2019). Também emergiam micropolíticas de resistência e (re)existência dessas juventudes diante de tais processos de assujeitamento, violência e apagamento de suas histórias singulares. Articulando esses relatos e as reflexões produzidas em supervisão, a experiência de extensão aponta como as histórias desses adolescentes e os processos de criminalização que lhes são direcionados são emblemas da perpetuação de colonialidades e das operações necropolíticas em curso no Brasil (BATISTA, 2003; MBEMBE, 2017; WACQUANT, 2012; PINHEIRO, 2018; ALENCAR, 2019; CAVALCANTE, 2020), bem como das práticas e processos de reinvenção de si e do mundo, a despeito das relações de poder objetificantes e estigmatizantes que indicem sobre territorialidades periféricas e suas juventudes.

Identificamos também relações entre racismo estrutural (ALMEIDA, 2018), necropolítica e os processos de sujeição criminal vividos por tais adolescentes em seus cotidianos (BARROS et al, 2019b). Segundo Misse (2014), esse processo de sujeição produz e dissemina uma expectativa negativa sobre indivíduos e grupos, considerando-os propensos a cometerem violências e passando a constituir seus modos de subjetivação. Através da intersecção de marcadores de raça, gênero e classe, os processos de sujeição criminal produzem 
trajetórias de adolescentes e jovens periferizados como inimigos internos (BATISTA, 2003; WACQUANT, 2012; MBEMBE, 2017; BARROS, 2019; BARROS et al., 2019a; BARROS et al., 2019b; BARROS et al., 2019c; BARROS et al., 2019d).

A título de exemplo, destacamos duas cenas registradas em nossa experiência de 2018. Durante um passeio externo ao Centro de Cultura e Arte Dragão do Mar, um dos adolescentes exclamou, referindo-se aos olhares de desconfiança que algumas pessoas no local lançavam na direção do grupo: "Pronto, já começou! Tudo segurando as bolsas!". Não obstante, um adolescente do grupo do segundo semestre de 2018 afirmou, indignado, ao comentar sobre as abordagens policiais no seu bairro: "Só porque o cara tem tatuagem, anda com cordão, com blusa de marca... Basta o cara ter um risquinho na sobrancelha, sobrancelha raspada ou cabelo, e já acham que é de facção". As vivências dos adolescentes convergiam também no atravessamento de diversas violências institucionais durante as suas trajetórias de vida, desde o impedimento à realização de matrícula em uma escola a até sofrer violência física em abordagens policiais e dentro dos centros socioeducativos de internação.

Os processos de criminalização desses adolescentes, personificando-os como inimigos públicos, podem ser considerado um dos principais operadores de uma necropolítica à brasileira (BARROS; 2019), considerando as relações entre criminalização e perpetuação do racismo no Brasil (BORGES, 2018). Com essa ação de extensão, principalmente a partir da escuta das trajetórias desses sujeitos vistos como vitrines das tensões sociais (DIÓGENES, 2009) ou como metáforas da violência e em condição de (in)visibilidade perversa (SALES, 2007), as oficinas buscaram fortalecer propostas de responsabilização juvenil que estejam de acordo com as recomendadas no ECA e no Sistema Nacional de Atendimento Socioeducativo (SINASE), construindo ressignificações das relações desses jovens com a violência, e tensionando as lógicas criminalizantes que produzem esses segmentos infantojuvenis como indignos de vida, memória e reconhecimento, pelo silenciamento das narrativas que eles próprios produzem sobre suas próprias histórias e as histórias de seus territórios de vida.

\subsection{Contribuição nos monitoramentos dos sistemas socioeducativo e prisional locais.}

No tocante à segunda frente do projeto, entre 2016 e 2017, participamos da formulação, execução e sistematização do $4^{\circ}$ monitoramento do sistema socioeducativo do Ceará, realizado pelo Fórum-DCA, a partir de visitas aos CREAS, Delegacias, Varas da Infância e Juventude, centros socioeducativos no Ceará, além disso, também é elaborado o relatório com sugestões 
de melhorias. Especificamente, entre agosto de 2016 e abril de 2017, foram visitadas 10 delegacias, 10 Varas da Infância e Juventude, 16 CREAS, 4 unidades de internação provisória, 5 unidades de semiliberdade, 1 unidade de recepção, 2 obras de unidades em construção e 6 unidades de privação de liberdade (CEDECA, 2017). É neste documento que denúncias são documentadas, a saber: violência institucional que os/as jovens sofrem nas unidades socioeducativas são documentadas, as condições insalubres dos equipamentos, a incapacidade do atendimento socioeducativo diante da demanda, bem como são apresentadas recomendações ao poder público municipal e estadual para melhorias de atendimento socioeducativo no Ceará. Por fim, os monitoramentos produzidos coletivamente e organizados pelo Fórum-DCA, desde 2008, mostram frequentemente que as determinações do SINASE não têm sido cumpridas (CEDECA, 2017).

Em 2018, continuamos participando da Comissão do Socioeducativo do Fórum-DCA, conjuntamente com CEDECA-CE, Conselho Municipal da Defesa dos Direitos da Criança e do Adolescente de Fortaleza (COMDICA), Conselho Regional de Serviço Social (CRESS-CE) e Conselho Regional de Psicologia $11^{\mathrm{a}}$ região (CRP-11). Participamos, ademais, da Comissão Intersetorial de Elaboração do Plano Decenal, com o objetivo de construir o Plano Decenal. O plano consistiu em um documento de metas, destinado a ser cumprido durante a próxima década (2018-2028), o qual objetiva buscar a melhoria do sistema socioeducativo no Estado e que será base para os próximos monitoramentos no sistema socioeducativo. Durante as reuniões, foi possível identificar algumas denúncias de familiares e socioeducandos/as, como: dificultoso acesso a atendimento de saúde, perseguição de profissionais por parte de direções por conta das denúncias que são feitas em relação a violência institucional contra adolescentes nas unidades de internação, novas rebeliões, em que uma delas, em junho de 2018 , culminou na morte de um jovem em cumprimento de medida socioeducativa no Centro Cardeal Aloísio Lorscheider.

Devido às transformações nas dinâmicas psicossociais da violência no Ceará, com a intensificação do encarceramento em massa feminino e da morte de meninas e mulheres (BORGES, 2018), a equipe de extensão começou a se inserir também no monitoramento do sistema prisional voltado para o público feminino, contexto que convoca a Psicologia à problematização e atuação frente às políticas de aprisionamento na atualidade e ao extermínio juvenil (SCISLESKI; GUARESCHI, 2014). Em agosto de 2018, a equipe de extensionistas se inseriu no Comitê Estadual de Monitoramento da Política Nacional para Mulheres Privadas de Liberdade e Egressas do Sistema Prisional, criado em 2017. Em 2018, o Comitê se destinou ao 
aprimoramento do Plano Estadual de Monitoramento da Política Nacional para Mulheres Privadas de Liberdade e Egressas do Sistema Prisional e o início do monitoramento da gestão do Instituto Penal Desembargadora Auri Moura Costa tendo em vista as sugestões propostas previamente à gestão desde o início operativo do Comitê. Além do VIESES, o comitê era composto pelo projeto Promoção de Arte, Saúde e Garantia de Direitos (Pasárgada/UFC), pela Pastoral Carcerária, pelo Instituto Negra do Ceará (INEGRA), pela Secretaria de Justiça e Cidadania (SEJUS/CE) e por representantes presas e egressas do sistema prisional. No segundo semestre de 2018, aconteceram 5 encontros, com frequência mensal, de articulação do plano e monitoramento, e, também, a participação em outros projetos como seminários produzidos pela Sejus sobre o encarceramento feminino.

Segundo Borges (2018), um dos principais vetores do aumento do encarceramento e das políticas militarizadas e ostensivas no campo da segurança pública no Brasil tem sido a política de guerra às drogas. A guerra às drogas é, pois, uma das marcas da colonialidade na atual relação entre vicissitudes do campo da segurança pública e do sistema prisional. Borges (2018) ratifica, assim, que a guerra às drogas é o cenário para que o dispositivo do encarceramento em massa conserve, na contemporaneidade, elementos fundamentais do regime escravista, apesar da formalização da abolição da escravidão. A maximização do Estado Penal em detrimento do Estado Social, ou seja, o recrudescimento do sistema penal, o gerenciamento do trabalho social, a alegoria da "responsabilidade individual" junto à diminuição e/ou sucateamento de políticas sociais, são constituintes no neoliberalismo (WACQUANT, 2012) que, em sua relação com a necropolítica, tem cotidianamente produzido juventudes supérfluas, contando, para isso, com processos de criminalização e demonização desses sujeitos convertidos em inimigos.

\section{CONCLUSÃO}

Com este artigo, buscamos relatar experiências de nossas ações de extensão junto a adolescentes a quem se atribui o cometimento de ato infracional, no âmbito do sistema socioeducativo, e junto a mulheres. Isso demanda exercícios analíticos sobre essas práticas institucionais e sobre suas implicações nesse contexto, atentando para a seletividade dos processos que constroem tanto a noção de "crime/infração" quanto a imagem do “criminoso/infrator". A psicologia tem sido convocada cada vez mais a atuar nesse campo sobretudo numa perspectiva de disciplinarização desses corpos e governo das condutas. Diversamente, entendemos que a intervenção da psicologia neste campo - a qual deve ser 
ensejada na formação, inclusive por meio de práticas de extensão como esta - envolve a ampliação da potência de ação dos próprios jovens em seus cotidianos.

Entendemos que a universidade pública tem um papel de grande relevância nesse contexto, dada sua capacidade de provocar debates e novas experimentações, por meio da articulação de ações de ensino-pesquisa-extensão. Nas nossas experiências de investigação e extensão, é comum o contato com jovens habitantes das margens urbanas que não se reconhecem como sujeitos de direitos efetivamente, no contexto de cidadania escassa supramencionado. Consideramos, assim, a relevância da criação de dispositivos de análise coletiva com jovens acerca de seus direitos, dos processos de sujeição criminal, próprio sistema socioeducativo e prisional onde estão inseridos.

\section{REFERÊNCIAS}

ALENCAR, F. A. Homicídios e conflitos territoriais na cidade de Fortaleza: a perspectiva de adolescentes em cumprimento de medida socioeducativa de meio aberto em Fortaleza. 2019. 100 f., Dissertação (Mestrado em Psicologia) - Centro de Humanidades, Universidade Federal do Ceará, 2019.

ALMEIDA, S. Racismo Estrutural. São Paulo: Pólen, 2019.

BARROS, J. P. P. Juventudes desimportantes: a produção psicossocial do "envolvido" como emblema de uma necropolítica no Brasil. In: COLAÇO; V. et al (Orgs.). Juventudes em movimento: experiências, redes e afetos. Fortaleza: Expressão Gráfica e Editora, 2019. p. 209-239.

BARROS, J. P. P. et al. "Somos Todos Envolvidos"!? Projeto Re-Tratos da Juventude e a Problematização da Criminalização Juvenil em Tempos Necropolíticos. In: LEMOS, F. C. S.; NASCIMENTO, M. L. (Org.). Biopolítica e Tanatopolítica: a agonística dos processos de subjetivação contemporâneos. Curitiba: CRV, 2019a. p. 183-200.

BARROS, J. P. P. et al. A política da pesquisa-intervenção em psicologia social: deslocamentos a partir dos estudos foucaultianos e da esquizoanálise. In: LEMOS, F. C. S. et al. (Org.). Conversas transversalizantes entre psicologia política, social-comunitária e institucional com os campos da educação, saúde e direitos. 1ed. Curitiba: CRV, 2017. p. 467-485.

BARROS, J. P. P. et al. Criminalização, extermínio e encarceramento: expressões necropolíticas no Ceará. Rev. psicol. polít., São Paulo, v. 19, n. 46, p. 475-488, 2019 b. 
BARROS, J. P. P. et al. Quanto importa cada vida? Problematizações éticas sobre violência contra populações infantojuvenis no Ceará. In: FREITAS, R. C. et al. (Org.). Juventudes, Linguagens e Direitos. Fortaleza: Imprensa Universitária - Universidade Federal do Ceará, 2019c. p. 19-52.

BARROS, J. P. P. et al. Violência, Juventude e Interseccionalidade: análise documental dos homicídios no estado do Ceará e na cidade de Fortaleza. In: LEMOS, F. C. S. et al. (Org.). Subjetividades e democracias: escritas transdisciplinares. CRV: Curitiba, 2019d. p. 20-40.

BARROS, J. P. P.; SILVA, D. B.; GOMES, C. J. A. Dispositivos grupais com jovens: rizomas em territorialidades periféricas. In: LEMOS, F. C. S. et al. (Org.). Pesquisar com as Psicologias: artesanias e artifícios. 1ed. Curitiba: CRV, 2020. p. 30-50.

BARROS, R. G. B. Dispositivos em ação: o grupo. In: SILVA, A. E. et al. (Org.). SaúdeLoucura 6. São Paulo: Editora Hucitec, 1997. p. 183-191.

BATISTA, V. M. Difíceis Ganhos Fáceis. Rio de Janeiro: Revan, 2003.

BORGES, J. O que é encarceramento em massa? Belo Horizonte: Letramento, 2018.

CAVALCANTE, C. O. B. "Humanos Indireitos": Modos de subjetivação de adolescentes e jovens a quem se atribui o cometimento de ato infracional. Dissertação de mestrado, Programa de Pós-Graduação em Psicologia, Universidade Federal do Ceará. Fortaleza, Brasil, 2020.

CEDECA. Análise do orçamento público do sistema socioeducativo. Fortaleza. Nota técnica $\mathrm{N}^{\mathrm{o}}$ 02/2014. Disponível em: <http://cedecaceara.org.br/site/wpcontent/uploads/2019/02/Nota-t\%C3\%A9cnica-An\%C3\%A1lise-do-or\%C3\%A7amentop\%C3\%BAblico-do-Sistema-Socioeducativo.pdf>. Acesso em: 06 jul 2010.

CEDECA. 4 Relatório de Monitoramento do Sistema Socioeducativo do Ceará: Meio Fechado, Meio Aberto e Sistema de Justiça Juvenil. Fortaleza: FÓRUM DCA, 2017.

CERQUEIRA, D. R. C. et al. Atlas da Violência 2018. Rio de Janeiro: Fórum Brasileiro de Segurança Pública/Ipea, 2018. Disponível em:

<http://www.ipea.gov.br/portal/index.php?option=com_content\&view=article\&id=33410\&Ite mid=432>. Acesso em: 23 jan. 2019.

DIÓGENES, G. Juventude, exclusão e construção de políticas públicas: estratégias e táticas. In: Mendonça Filho, M.; Nobre, M. Política e afetividade: narrativas e trajetórias de pesquisa. Salvador: EDUFBA: EDUFS, 2009.

GUATTARI, F.; ROLNIK, S. Micropolítica: cartografias do desejo. Petrópolis: Vozes, 2005.

HILLESHEIM, B.; CRUZ, L. R. Risco, vulnerabilidade e infância: algumas aproximações. Psicologia e Sociedade, v. 20, n. 2, p. 192-199, 2008. 
MBEMBE, A. Crítica da Razão Negra. Lisboa: Antigona, 2014.

MBEMBE, A. Política da Inimizade. Lisboa: Antigona, 2017.

MELO, D. L. B; CANO, I. Índice de Homicídio na Adolescência: IHA 2012. Rio de Janeiro: Observatório de Favela, 2014.

MISSE, M. Sujeição Criminal. In: LIMA, R. ; RATTON, J.; AZEVEDO, R. (Orgs). Crime, Polícia e Justiça no Brasil. São Paulo: Contexto, 2014.

PINHEIRO, J. P. Juventudes e violências urbana: Trajetórias de sujeitos em cumprimento de medida socioeducativa na cidade de Fortaleza. Dissertação de mestrado, Programa de PósGraduação em Psicologia, Universidade Federal do Ceará. Fortaleza, Brasil, 2018.

ROLNIK, S. Esferas da insurreição: notas para uma vida não cafetinada. São Paulo: n-1 edições, 2018.

SALES, M. A. (In)visibilidade perversa: adolescentes infratores como metáfora da violência. São paulo: Cortez, 2007.

SCISLESKI, A. C. C.; GUARESCHI, N. M. F. (Org.). Juventude, Marginalidade Social e Direitos humanos: Da Psicologia as Políticas Públicas. 1. ed. Porto Alegre: EDIPUCRS, 2014.

WACQUANT, L. Forjando o estado neoliberal: trabalho social, regime prisional e insegurança social. In: BATISTA, V. (Org). Loïc Wacquant e a questão penal no capitalismo neoliberal. Rio de Janeiro: Revan, 2012. 